\title{
EL PLURALISMO JURÍDICO EN LOS JUZGADOS COMUNALES DE MICHOACÁN. UNA PROPUESTA TEÓRICA PARA SU ESTUDIO
}

\author{
Orlando Aragón Andrade \\ orlandoarande@yahoo.com.mx \\ UNIVERSIDAD MICHOACANA DE SAN NICOLÁS DE HIDALGO,
}

MÉXICO

\section{RESUMEN}

En el presente trabajo* se realiza una primera aproximación al tema de los juzgados comunales de Michoacán como figura judicial que oficializó, en 2007, los sistemas normativos indígenas en la entidad. El objetivo de esta contribución se centra en dilucidar si la producción jurídica de estos nuevos juzgados, a pesar de ser campos de pluralismo jurídico, guarda un equilibrio semejante al que caracteriza la legalidad estatal o por el contrario tiene más elementos de la justicia que se aplica en las comunidades indígenas de Michoacán. Para lograr alcanzar esta meta, el autor acude a la propuesta analítica de Boaventura de Sousa Santos que concibe a la retórica, la burocracia y la violencia como elementos centrales de todo Derecho.

Palabras clave: pluralismo jurídico, juzgados comunales, sistemas normativos indígenas, Michoacán. 


\begin{abstract}
In this paper the author presents a preliminary analysis of the topic of Michoacan's communal courts, given legal status in 2007 by the state's indigenous normative systems. The objective of this contribution is focused on clarifying whether the legal production from these new courts - despite being fields of legal pluralism - maintain an equilibrium similar to that characterizing the state legality, or to the contrary, whether these courts possess additional elements of justice applied in Michoacan's indigenous communities. In order to achieve this objective, the author draws upon the analytical proposal developed by Boaventura de Sousa Santos, who conceives of rhetoric, bureaucracy and violence as central elements in all types of Law.
\end{abstract}

Key words: legal pluralism, communal courts, indigenous normative systems, Michoacan. 


\section{INTRODUCCIÓN}

Desde hace algunos años los Estados latinoamericanos han experimentado varias trasformaciones en su relación con los pueblos indígenas. Una de las pistas más importantes en este nuevo escenario, sin lugar a duda, es la del reconocimiento jurídico o la incorporación de los pueblos indígenas en las constituciones políticas y en otros ordenamientos jurídicos secundarios. ${ }^{1}$

Varios son los aspectos que estos cuerpos legales han reconocido como derechos de los pueblos indígenas, por ejemplo, el derecho a la libre determinación, a la educación intercultural, a la no discriminación, al patrimonio cultural, a sus territorios, al conocimiento tradicional, entre otros. Uno de los puntos más importantes de esta oleada de reconocimientos, particularmente en México, es el derecho al Derecho, o más bien dicho, el derecho de los pueblos indígenas a aplicar sus propios sistemas normativos. $^{2}$

Al respecto se puede observar como desde el Convenio 169 de la Organización Internacional del Trabajo en $1989,{ }^{3}$ pasando por la reforma del artículo $4^{\circ}$ en 1992 , por la modificación del artículo $2^{\circ}$ en $2001^{4}$ y por la recién aprobada Declaración sobre Pueblos Indígenas de las Naciones Unidas, ${ }^{5}$ se ha legislado en este sentido, es decir, en la obligación del Estado mexicano a reconocer los sistemas normativos indígenas. No obstante, a pesar de que la primera disposición tuvo vigencia vinculante desde 1991 — que fue el caso del Convenio 169-, tuvieron que pasar más de seis años para que se realizara un primer intento de poner en práctica tal prerrogativa.

Así fue como en 1997 en el estado de Quintana Roo se crearon los juzgados indígenas, ${ }^{6}$ con la finalidad expresa de cumplir lo dispuesto en el Convenio $169 \mathrm{y}$ en el entonces artículo $4^{\circ}$ de la Constitución federal. A partir de ese momento se instituyeron figuras análogas en varias entidades federativas como Campeche, ${ }^{7}$ Chiapas, ${ }^{8}$ Puebla, ${ }^{9}$ Michoacán, ${ }^{10}$ entre otras. Estos aparatos jurisdiccionales son figuras que supuestamente aplican los sistemas normativos indios, pero que se encuentran enmarcados en la estructura de los distintos tribunales de justicia locales.

En lo que sigue buscaré establecer y aplicar una propuesta teórica para el análisis de los juzgados indígenas creados por el Estado, que permita dar cuenta de la producción jurídica de estos aparatos jurisdiccionales. Es importante señalar que 
únicamente me abocaré al caso de los juzgados comunales, así denominados oficialmente, de Michoacán, ya que es el espacio que actualmente estudio para desarrollar mi tesis doctoral. Por lo tanto los resultados que aquí se presentan son preliminares aún.

Para lograr los objetivos antes enunciados dividiré este trabajo en cuatro partes. Primero, me ocuparé de establecer la necesidad de estudiar de manera diferenciada, en relación con otros campos de pluralismo jurídico, la legalidad producida por estas instancias jurisdiccionales. Después, propondré un abordaje teórico a partir del desarrollado por Boaventura de Sousa Santos, para analizar la producción jurídica de este campo en particular. En tercer lugar, aplicaré esta propuesta para el caso de los juzgados indígenas de Michoacán. Finalmente, cerraré este trabajo con algunas reflexiones finales.

\section{REFORMA DEL ESTADO, JUZGADOS INDÍGENAS \\ Y RADICALIZACIÓN DE LA INTERDEPENDENCIA JURÍDICA}

Mencioné, líneas atrás, que el cambio formal en la relación de los Estados latinoamericanos con los pueblos indígenas se acentuó desde 1989 a la fecha. Bien, es importante recordar lo que ya han advertido un buen número de autores respecto a que en este proceso de reconocimiento de los pueblos indígenas sus luchas y movilizaciones no son los únicos factores que han intervenido en la trasformación de los Estados.

En México, desde la década de los setenta, comenzó un proceso paulatino de trasformación de la estructura estatal, que es conocido con el nombre de la reforma del Estado. Esta consistió, precisamente, en el cambio de sus instituciones para abandonar el modelo de desarrollo interno revolucionario y adoptar uno de economía de libre mercado (Valdés 1993). Dicho proceso de trasformación significó el desarrollo y encuentro de distintas agendas, así como de diversos actores y fuerzas, los cuales no necesariamente son complementarios, sino que incluso pueden ser contradictorios. La reforma del Estado es, pues, un fenómeno paradójico y no lineal (Assies 1999, Walsh 2002, Hernández Paz y Sierra 2004).

Ahora, la trasformación del Estado mexicano no puede ser desvinculada de los cambios en la economía mundial y de la nueva etapa del capitalismo mundial. Los agentes y las fuerzas de la vagamente denominada «globalización económica» fueron 
factores decisivos para la modificación en las estructuras y obligaciones del Estado mexicano.

En la reforma del Estado, como ya lo mencioné, convergen diferentes fuerzas, actores e intereses que en muchas ocasiones son contradictorios. Así por ejemplo, a la par de las luchas por la democratización política de México y el fin de las prácticas discrecionales, cooptadoras y clientelistas del régimen priísta, que encabezaron sectores y movimientos sociales hacia finales de los ochenta, comenzó una presión externa por instituciones como el Banco Mundial, el Fondo Monetario Internacional y el Banco Interamericano de Desarrollo, con el objetivo de que los gobiernos de los Estados latinoamericanos adoptaran medidas y reformas que mejoraran sus instituciones en cuanto a eficacia y trasparencia. Esta presión aprovechó la necesidad de la mayoría de los Estados latinoamericanos de nuevos préstamos por parte de estos organismos, ya que dichos créditos eran condicionados a la adopción de medidas dictadas por estos entes. La mayoría de las directrices postuladas fueron condensadas en un documento conocido como el Consenso de Washington, producto de una reunión entre diversos representantes de América Latina (Carvalho 2000).

En la cuestión que aquí me interesa - los juzgados indígenas-, dos agendas de la reforma del Estado muestran esa convergencia paradójica: la judicial y la indígena. En efecto, ambas agendas tienen actores y finalidades distintas, incluso dentro de cada una de ellas no existe un impulso homogéneo, ${ }^{11}$ pero se han cruzado en la creación de los juzgados indígenas. Por un lado, tenemos las modificaciones en el poder judicial, que se iniciaron con el asentamiento del nuevo modelo económico - la primera gran reforma en el ámbito federal se efectuó en 1994-, ya que como lo señala Héctor FixFierro la reforma judicial y el estado de derecho son considerados como factores indispensables para la liberación económica y democrática (Fix-Fierro 2003: 251).

La llamada reforma judicial se ha ocupado, principalmente, de reposicionar al poder judicial frente al legislativo y al ejecutivo mediante una serie de cambios en su interior. ${ }^{12}$ Una de estas nuevas medias ha sido la «desformalización de la justicia» para ciertos asuntos, que en el derecho interno se caracterizan por su baja cuantía (Suprema Corte de Justicia de la Nación 2006), pero que son producto de la lógica de un nuevo orden legal trasnacional promovido para facilitar la circulación de grandes capitales por todo el mundo (Dezalay y Garth 1996). De ahí, por ejemplo, la tendencia de instalar, en 
varias entidades de la República, Centros de mediación y arbitraje, en donde las partes en pugna no tienen que contratar los servicios profesionales de un abogado, ya que la justicia que se aplica en esas instituciones judiciales es conmensurable para las partes por sí solas.

La finalidad manifiesta de estos aparatos es mejorar el acceso a la justicia del Estado para la población, que en ocasiones no acude a los tribunales por lo costoso que le resulta. En esta misma lógica se han creado, además de los Centros de mediación, juzgados indígenas; estos últimos con la finalidad de acercar la justicia del Estado a los integrantes de los pueblos indígenas. En resumen, lo que se persigue con estas medidas de «desformalización de la justicia» es superar la crisis actual de los aparatos jurisdiccionales del Estado (Santos 1991a).

Por su parte, la reforma indígena comenzó al momento en que el Estado mexicano abandonó sus políticas sociales, entre ellas las indigenistas. Esta situación permitió la aparición o fortalecimiento de grupos que promovieron la organización de los pueblos indígenas, como fueron algunos sectores de la Iglesia católica y varias organizaciones no gubernamentales, entre otros. Este giro debilitó el poder cooptador que el Estado ejercía a través de sus políticas sociales en las regiones indígenas. No obstante, la finalidad de la reforma indígena fue empoderar a los pueblos indios y modificar la relación asimétrica que mantienen frente al Estado. En este sentido, la creación de los juzgados indígenas significaría un reconocimiento de un espacio de poder y autonomía para los pueblos indígenas, con una lógica y criterios independientes de los de la justicia estatal.

Pocos trabajos en México se han interesado en estudiar estos nuevos campos de producción jurídica; mismos que pueden ser clasificados en dos grupos. El primero lo ha visto como esfuerzos del Estado mexicano por reconocer y poner en vigencia los sistemas jurídicos indígenas. El interés central de este grupo de investigaciones es el de encontrar defectos y limitantes en las leyes o cuerpos jurídicos donde se reglamenta la organización de estos tribunales para proponer mejoras y medidas que permitan su perfeccionamiento (Reyes y Ek 2001, Gutiérrez 2001, González 2004, Domingo 2005, Buenrostro 2006). El segundo conjunto de trabajos ha considerado que la instauración de estos aparatos jurisdiccionales responde a una estrategia de expansión del Derecho estatal a zonas donde anteriormente guardaba una posición marginal, como es el caso de 
las regiones indígenas (Terven 2005, Gabbert 2006, Sierra 2006). En estas investigaciones, particularmente las que se refieren al caso de Cuetzalan, se pone énfasis en cómo las organizaciones indígenas y sus aliados se apoderan de estos campos de producción jurídica mediante diversas estrategias de resistencia (Terven 2005, Sierra 2006).

Lo anterior quiere decir que las preocupaciones centrales de las investigaciones sobre este tema se han enfocado en (I) un análisis reformista de las leyes de los juzgados indígenas, y (II) en las estrategias sociales y políticas que las organizaciones indígenas despliegan para oponer resistencia a la expansión del Estado.

A pesar de que estos trabajos han realizado aportes importantes en el entendimiento de estos tribunales considero que carecen de un adecuado filtro para estudiar las influencias, avances y cambios de los Derechos en pugna en los juzgados indígenas. Es claro que mediante el análisis de las leyes no se puede evaluar el equilibrio de la producción jurídica de estos aparatos jurisdiccionales, pero tampoco mediante las intenciones declaradas de las acciones que realizan los actores que interactúan en estos campos. En sus trabajos sobre los procesos de informalización de la justicia Boaventura de Sousa Santos explicó cómo los desarrollos desiguales y combinados de los sistemas normativos que confluían en la justicia producida por estos juzgados no se podía explicar «ni por las ideologías que los justificaban, ni por las orientaciones políticas que los guía[ba]n» (Santos 1991a: 133). Me parece que para el caso de los juzgados indígenas se puede aplicar el mismo criterio, al igual que en las reformas de informalización de justicia que estudió Santos; en México, la instalación de los juzgados indígenas ha sido impulsada por grupos con planteamientos ideológicos y objetivos sociopolíticos diferentes, y en algunos casos hasta antagónicos, pero que paradójicamente a la hora de implantar estas instancias judiciales han convergido. Por lo que las dos anteriores aproximaciones son insuficientes para este fin.

La influencia del Derecho estatal sobre los sistemas normativos indígenas, $\mathrm{y}$ viceversa, ha sido un proceso continuo a lo largo de la historia. Es sabido que el desarrollo de los Derechos no se presenta como dos líneas paralelas que son independientes y que no se cruzan (Sierra 1997). Por el contrario, este desarrollo se ha dado en el contexto de un constante diálogo, encuentro, choque, interdependencia, superposición, etcétera. Existen un buen número de investigaciones empíricas que dan 
cuenta de esa relación. ${ }^{13}$ No obstante, tal situación no debe llevar a pensar que por este mestizaje se desactiva el potencial regulador de estos nuevos aparatos jurisdiccionales. Así pues, a pesar de que esta nueva justicia sea un producto híbrido se le puede evaluar en su contenido en cuanto a que tienda más a reproducir una justicia cercana a la que producen las comunidades indígenas o por si el contrario su hibridez esconde la expansión del sistema jurídico estatal.

Lo anterior remite a un problema tradicional de la antropología jurídica mexicana que ha sido destacado acertadamente por Francois Lartigue y Diego Iturralde, en el sentido de que esta se mueve en una trama de intersecciones entre la costumbre y la ley que puede ser muy densa y amplia con límites difíciles de definir con claridad (Lartigue e Iturralde 1995: 363-364). Si a lo anterior se suma el hecho de que, tal como lo advierte Slavoj Žižek, la dominación actual ya no se basa primordialmente en la prohibición o censura, sino en la permisividad irrestricta (Žižek 2005: 63); ${ }^{14}$ así como el enfoque de algunos trabajos de la antropología norteamericana que consideran que en los espacios en donde se manifiesta la ambigüedad o ilegibilidad provocada por el choque de sistemas distintos opera el régimen jurídico del estado de excepción y del campo de concentración (véase, Poole 2006, Das y Poole 2008: 11-19), tal como lo propone Giorgio Agamben en Homo Sacer (Agamben 2006: 211-229); me parece un asunto pendiente para los trabajos antropológicos el establecer con mayor claridad los límites de las intersecciones entre el Derecho estatal y los sistemas normativos indígenas en campos de pluralismo jurídico como los juzgados indígenas.

En este sentido considero pertinente recuperar la propuesta de William Twining de intentar construir planteamientos teóricos que permitan estudiar la actual radicalización de la interdependencia jurídica sin repetir los errores de las viejas teorías generales del Derecho (Twining 2005: 124-125). Una herramienta analítica que creo que es útil en este sentido es la propuesta por Boaventura de Sousa Santos sobre la idea de que todo sistema normativo o Derecho está compuesto y se articula a partir de tres elementos: la retórica, la burocracia y la violencia (Santos 1997: 20). 


\section{APROXIMACIÓN TEÓRICA. LA RETÓRICA, LA BUROCRACIA}

\section{Y LA VIOLENCIA COMO ELEMENTOS CONSTITUTIVOS DEL DERECHO}

Es importante señalar que la propuesta de retomar este modelo analítico de Santos para estudiar el reconocimiento o la oficialización de los sistemas jurídicos indios en los Estados latinoamericanos ya había sido realizada, en parte, por Willem Assies (2001) en su trabajo titulado «La oficialización de lo no oficial: ¿(re)encuentro de dos mundos?». Ahí este autor bosqueja la potencialidad de esta teoría para el estudio de la oficialización de sistemas normativos indígenas. Sus ejemplos son, sin embargo, reconocimientos distintos a los que se han producido en México. Assies se refiere, sobre todo, a la oficialización al estilo colombiano, es decir, al otorgamiento de jurisdicción a las autoridades de las comunidades indígenas y a la tendencia a codificar sus sistemas jurídicos. El caso de México es distinto; como ya lo señalé, el reconocimiento jurídico no se ha traducido en otorgar jurisdicción a las autoridades judiciales que las comunidades y pueblos indígenas ya tienen, sino más bien a crear juzgados indígenas incorporados y dependientes de los poderes judiciales de las entidades federativas.

Dentro de la lógica del trabajo de Boaventura de Sousa el Derecho estatal no es capaz de resolver de fondo las contradicciones y los movimientos sociales que genera el capitalismo junto con sus dinámicas. En consecuencia, el Derecho producido por el Estado capitalista tiene como función la de «mantener en niveles tensionales funcionalmente compatibles con los límites estructurales impuestos por el proceso de acumulación y por las relaciones de producción que en él tienen lugar» (Santos 1991a: 125).

De esta forma, cuando las luchas sociales suben de intensidad en respuesta a las crisis producidas por el capitalismo, y en alguna medida logran poner en peligro el orden establecido, son desarticuladas a través de varios «mecanismos de dispersión» empleados por el Estado. Por lo que, en función de lo explicado, la instauración de los juzgados indígenas no tiene como finalidad reconocer los sistemas normativos indios, sino dispersar la movilización entorno a esa demanda de las organizaciones indígenas, y aún más busca expandir la influencia de la legalidad estatal a las regiones indígenas.

Como ya lo dije atrás, Boaventura de Sousa Santos sostiene que el Derecho está compuesto de tres estructuras básicas: la retórica, la burocracia y la violencia. La 
primera «se basa en la producción de persuasión y de adhesión voluntaria, a través del potencial argumentativo de secuencias y artefactos verbales y no verbales socialmente aceptados» (Santos 1991a: 126). La burocracia, por su parte, se caracteriza por la «imposición autoritaria, a través de la movilización del potencial demostrativo del conocimiento profesional de las reglas formales generales y de procedimientos jerárquicamente organizados» (ídem). Finalmente, la violencia «se basa en el uso o amenaza de la fuerza física» (ídem).

Los sistemas jurídicos se distinguen entre sí por las diferentes articulaciones y relaciones de los tres elementos anteriores (Santos 1997). De esta forma la legalidad de los Estados capitalistas se ha caracterizado por la preponderancia de la burocracia y la violencia en detrimento de la retórica (Santos 1991a). En contraste se puede afirmar que con base en las investigaciones documentadas por la Antropológica mexicana, desde la investigación pionera de Nader hasta el trabajo comparado de distintas regiones indígenas encabezado por Teresa Sierra, que los sistemas normativos se caracterizan por una articulación en donde la retórica predomina sobre la violencia y la burocracia. ${ }^{15}$

Se puede pensar que detrás de esta cuestión central que me interesa investigar en la justicia producida en los juzgados comunales subyace una concepción esencialista del Derecho. Yo tengo que admitir que, en efecto, sostengo aquí una forma de «esencialismo débil». Entiendo los peligros que rodean a esta posición, sé que uno de los primeros aportes de la Antropología jurídica mexicana fue el demostrar que los sistemas normativos indígenas eran dinámicos y construidos históricamente en una relación de constante encuentro con el Derecho estatal. Este argumento lo sé y lo comparto. No obstante, rendirse a la posición extrema del «no esencialismo» también tiene sus problemas. Si los sistemas normativos indígenas son exclusivamente un producto que se ha desarrollado de sus constantes hibridaciones con el Derecho estatal y no hay elemento propio que la caracterice, sino únicamente la constante mezcla, ¿vale la pena seguir sosteniendo una diferenciación entre una justicia y otras?

Me parece que aquí se encuentra el mismo problema que las posiciones más «flexibles» del pluralismo jurídico enfrentan cuando intentan diferenciar lo jurídico de lo no jurídico. El afán de mantener un espectro muy amplio trae como consecuencia que llega un momento en que se ve al fenómeno del Derecho «en todas partes», se pierde la capacidad de distinguir entre lo jurídico y lo no jurídico (véase, Tamanaha 2007). Ya se 
ha dicho, certeramente creo yo, «si el derecho está en todas partes, no está en ninguna». Así pues, la posición «no esencialista» padece este mismo mal, es decir, es poco útil, analíticamente hablando, para intentar establecer algunos límites en las intersecciones de los sistemas normativos indígenas y el derecho estatal (véase Santos 2009b: 62).

Considero que adoptar este abordaje teórico propuesto por Santos para el estudio de los juzgados indígenas me permitirá establecer comparaciones clarificadoras entre campos y sistemas jurídicos. Además, con él se puede superar, en alguna medida, el debate de aproximarnos al estudio de los sistemas normativos indígenas con conceptos y categorías del Derecho estatal, puesto que esta herramienta analítica no es el reflejo de un sistema jurídico extrapolado a otros, como ocurría con otras teorías. ${ }^{16}$ En todo caso la formulación de Santos se muestra más «neutra» que los intentos anteriores, aunque esto no quiere decir se encuentre exenta de reducciones, aun así considero que su teoría ofrece más ventajas que desventajas.

\section{PLURALISMO JURÍDICO Y DISPUTA «POR DECIR».}

\section{EL DERECHO EN LOS JUZGADOS COMUNALES DE MICHOACÁN}

En esta penúltima parte estudiaré el caso concreto de los juzgados comunales de Michoacán con los primeros datos que he obtenido, por lo que, como lo señalé al inicio de este artículo, lo que a continuación se presenta sólo puede tomarse como una aproximación preliminar. Esta entidad de la República mexicana modificó su Constitución política por primera vez en 1998 para reconocer a los pueblos indígenas como parte integrante del estado de Michoacán. La reforma local ${ }^{17}$ del artículo $3^{\circ}$ se inspiró en la realizada en 1992 en el artículo $4^{\circ}$ de la Constitución federal. Es conocido este último cambio constitucional como el primero que se dio en México para reconocer la existencia formal de los pueblos indígenas, por lo que sus alcances fueron limitados. A pesar de esta situación el texto de la reforma constitucional en Michoacán fue todavía más pobre que el de su predecesor en el ámbito federal.

Con el auge del movimiento zapatista en Chiapas y sus ecos en el resto del país se logró una nueva reforma constitucional en el ámbito federal que, aunque ha sido repudiada por la mayoría de las organizaciones indígenas, amplió en mucho los derechos garantizados en el antiguo artículo $4^{\circ}$. Dicho reconocimiento quedó plasmado en el artículo $2^{\circ}$ en 2001. Con esta reforma a escala federal inició otra ola de cambios 
constitucionales en las entidades federativas. En Michoacán se han intentado realizar modificaciones al ya muy rebasado artículo $3^{\circ}$, pero la debilidad del movimiento indígena, la incomprensión de la clase política y los intereses económicos que operan en la entidad, no lo han permitido.

El intento más serio de reforma lo encabezó el gobernador anterior, Lázaro Cárdenas Batel. Para este proceso frustrado, que duró de 2003 a 2005, se realizaron foros a los que acudieron los actores habituales - líderes indígenas, autoridades comunales, funcionarios indigenistas, políticos, académicos, etcétera-; desafortunadamente la reforma en materia indígena no se aprobó, por varias de las causas que anteriormente señalé (véase, Ventura 2005, Aragón y Montero 2008).

Hacia finales del sexenio de Cárdenas Batel, en 2005, se discutió otra reforma, la del poder judicial local. A diferencia de la indígena este proceso sí cuajó, y en ese mismo año se aprobó la reforma constitucional a los artículos 67, 90 y 91. La reforma judicial en Michoacán se completó con la publicación de la nueva Ley Orgánica del Supremo Tribunal de Justicia del Estado de Michoacán y la Ley de Justicia Comunal, de febrero de 2007. Dentro de las muchas modificaciones realizadas al aparato de justicia de la entidad federativa se incluyó la instalación de los juzgados comunales, cuya finalidad sería la de garantizar el acceso a la justicia del Estado a los pueblos indígenas. Los actores que intervinieron y diseñaron esta última reforma - la judicial - no fueron los habituales que intervienen en una reforma que afecta a los indígenas, se trataban más bien de jueces, de abogados y otras personas relacionadas con la administración e impartición de justicia estatal. El objetivo de estas modificaciones legales no era reconocer derechos a los indígenas, más bien se pensó en mejorar y expandir la justicia que aplica el Estado a través de sus instituciones. Lo mencionado queda claro cuando para la creación de estos nuevos aparatos jurisdiccionales destinados a los indios no se realizó consulta alguna a los pueblos y comunidades indígenas, violando así lo dispuesto en el Convenio 169 de la OIT (Aragón y Montero 2008).

Cabe señalar que la reforma judicial en Michoacán no solo creó un nuevo órgano de resolución de conflictos, sino que formalmente, y en algunos casos en «la realidad», desapareció la anterior instancia de justicia indígena. En la estructura judicial anterior existían, en el último peldaño, los juzgados menores de tenencia. Estos tribunales, aunque también fueron una creación estatal, ya habían sido adoptados y apropiados por 
muchas comunidades indígenas. ${ }^{18}$ Los juzgados menores de tenencia tenían sede en las comunidades, en su inmensa mayoría los jueces eran legos y su designación quedaba en manos de la comunidad. Los jueces menores de tenencia no recibían un salario del poder judicial local, tampoco eran supervisados por éste; lo único que el Supremo Tribunal les proporcionaba era una credencial que les acreditaba como juzgadores. Si bien estos tribunales no fueron creados explícitamente para las comunidades indígenas, en la práctica se sobreponían a las autoridades comunales.

El 23 de agosto de 2007 se instaló el primer juzgado comunal en la ciudad de Coahuayana, en la región nahua de la costa michoacana. Una semana después se abrió el juzgado comunal de la región purépecha en la ciudad de Uruapan, la segunda más grande de Michoacán. Si uno se atiene a lo que dicen algunas disposiciones de la Ley de Justicia Comunal podría llevarse la impresión de que no hubo mucho cambió en relación con los juzgados menores de tenencia, y que lo único que se hizo fue oficializar la justicia que aplican las comunidades indígenas. Por ejemplo, la Ley habla de que para ser juez no se requiere ser abogado (véanse, artículos de 8 a 13), que el procedimiento judicial que desarrollan estos juzgados estará exento de formalidades y que será oral, además se destaca el carácter conciliatorio de los procedimientos (véase, artículo 22).

Líneas atrás sostuve que la creación de los juzgados comunales implica un avance en el sistema de control y dominación estatal. A primera vista mi afirmación puede parecer un contrasentido. Si el Estado decidió instaurar estos tribunales con las características que brevemente he señalado más bien respondería a un retiro de las funciones del Estado, para dejarlas en manos de los directamente afectados: los pueblos indígenas. ¿Cómo es entonces que sostengo lo contrario? Bien, aquí me es útil acudir a la teoría de Santos.

Ya comenté que el Derecho del Estado capitalista, bajo el andamiaje teórico de Santos, está dominado por la burocracia y la violencia en detrimento de la retórica. En cambio, señalé también, que en los sistemas normativos indígenas predomina la última sobre las dos primeras. Ahora bien, al contrastar algunas de las características de los juzgados de justicia comunal se podrán detectar varias contaminaciones de burocracia y violencia en un sistema que en apariencia está dominado por la retórica.

Comenzaré este contraste con el nombramiento del juez de justicia comunal. En los sistemas normativos indígenas de Michoacán el juzgador no se distingue por ser un 
profesional en el área del Derecho, puede incluso, como ocurre en la inmensa mayoría de los casos, no tener ningún tipo de formación profesional jurídica, basta con que sea un miembro distinguido — que haya ocupado varios cargos en la comunidad - y con una solvencia pública reconocida. Esto tiene como consecuencia que el conflicto se resuelva en un leguaje conmensurable para las partes y que en la mayoría de los asuntos que conoce los abogados sean innecesarios. Es precisamente el elemento de la retórica que excluye a la burocracia y a la violencia. ¿Qué ocurre en los juzgados comunales?

Aunque, como ya lo señalé atrás, la Ley de Justicia Comunal ordena que para ser juez no se requiere ser abogado, en la realidad es difícil que se obvie el conocimiento del Derecho estatal. Lo anterior, en razón de que el juez comunal es un funcionario judicial más y está sujeto a las mismas sanciones administrativas que uno de «jurisdicción ordinaria». Esto implica que si el juez comunal ignora algunos procedimientos y leyes puede ser sujeto a sanciones que pueden llegar hasta la destitución de su cargo. Esta cuestión dificulta en los hechos la entrada a esta función a los miembros de prestigio social en las comunidades, pero sin conocimiento profesional del Derecho. En cambio, favorece a los indígenas con estudios profesionales en esta disciplina, pero que no cuentan con el respaldo y representación de las comunidades.

En los juzgados comunales sólo uno de los jueces cuenta con la licenciatura en Derecho. Es el caso de la juez de la región purépecha. Por ejemplo, el juez de la región nahua no cuenta con estudios profesionales en el área jurídica. Ahora, esto podría parecer una prueba en contra de mi hipótesis; sin embargo, la designación fue realizada de esta forma porque el otro candidato a ocupar dicho cargo - para el juzgado nahua sólo se presentaron dos candidatos - tampoco había cursado la carrera de Derecho; así que de cualquier forma iba a quedar un juez lego. A esto se le debe sumar que debido a la lejanía de Coahuyana una característica de una buena parte de su burocracia judicial es el bajo nivel de profesionalización. Cabe señalar que cuando entrevisté a algunos funcionarios encargados de la capacitación del Tribunal de Justicia de Michoacán manifestaban su preocupación «por lo que podía pasar con este juez», ya que no conocía de Derecho. Una preocupación similar me manifestaron sus colegas purépechas, que en su totalidad habían estudiado la carrera en leyes.

Particularmente sorprendente fue encontrar, en las primeras investigaciones de campo que he realizado, que el juez lego, el de la región nahua, es el más preocupado 
por cumplir todas las formalidades de un «juzgado ordinario» durante el procedimiento judicial. Mientras que la jueza abogada y su equipo en el caso purépecha practican una política de mayor informalidad en su juzgado. Al parecer el conocimiento de la ley le permite a la juez y su notificador, también abogado indígena, tener mayor seguridad en sus actuaciones. Por ejemplo, hace un par de meses se ventiló en el juzgado un asunto que rebasaba por mucho su competencia, se trataba de un caso que presumiblemente violaba hasta derechos humanos, ya que las autoridades de una comunidad habían decidido expulsar a una familia que era foránea. Las razones que daban las autoridades comunales eran que varios miembros de esta familia agredían a otros integrantes de la comunidad y que ya en muchas ocasiones se les había reconvenido. Los funcionarios del juzgado comunal conocieron el asunto mediante una interpretación singular de la ley, pero que tenía cierta lógica legal. Al final dieron la razón a las autoridades tradicionales y lograron convencer a esta familia de que pactara para que después abandonaran la comunidad.

En las audiencias a las que he tenido la oportunidad de asistir del juzgado purépecha me he percatado de que los funcionarios indígenas han invitado en algunas ocasiones a las autoridades de las comunidades, para que junto con ellos resuelvan el conflicto que les hacen llegar los integrantes de sus localidades, acción que no he visto ni una sola vez en el juzgado de la región nahua.

Otro asunto en el que se detectan contaminaciones de burocracia y violencia es en la facultad que por ley tiene el Supremo Tribunal de Justicia para capacitar a los jueces comunales (véase, artículo $8^{\circ}$ ) ¿Cómo será esta capacitación? La respuesta es sencilla y clara, será en la «correcta» aplicación del Derecho estatal. De hecho, durante el proceso mediante el cual se seleccionaron a los jueces que están ahora en funciones se les impartió un curso de capacitación. Dicha preparación fue realizada por algunos pocos funcionarios indigenistas y académicos, $\mathrm{y}$ preponderantemente por jueces del fuero común. A pesar de que algunos de los funcionarios indigenistas y también un académico eran de origen indígena ninguno de ellos había fungido como juzgador en una comunidad, por el contrario estos son licenciados en Derecho e incluso cuentan con estudios de posgrado en la misma área. Por lo que toca al curso que impartieron los jueces ordinarios consistió en la correcta aplicación de las leyes estatales. Así pues, la capacitación de estos funcionarios estuvo y estará dominada por el conocimiento 
profesional del Derecho, que excluye o relega la experiencia y conocimiento de los jueces menores de tenencia que todavía en muchos casos siguen resolviendo los conflictos en sus comunidades.

Una situación similar se encuentra en la facultad que está reservada, por ley, para el Tribunal de Justicia del Estado de decidir dónde se abrirán nuevas sedes de los juzgados comunales (véase, artículo $7^{\circ}$ ). A pesar de que la misma ley establece que las comunidades indígenas podrán contar con este tipo de juzgados, el Tribunal de Justicia del Estado resolvió abrir únicamente dos, uno en la región nahua y otro en la purépecha. Pero resulta que en Michoacán hay cuatro pueblos originarios; además de los mencionados en el Estado hay comunidades mazahuas y otomíes, más todos los indígenas que han migrado al Estado y que se calculan pertenecen a 39 pueblos indígenas distintos. No obstante, el Tribunal decidió abrir solo dos «para ver cómo funcionaban», ignorando el Derecho de los otros pueblos indígenas que habitan en Michoacán.

Ahora, ¿cómo va a determinar el Supremo Tribunal si los juzgados comunales presentan experiencias exitosas? La respuesta es también fácil, lo hará utilizando los mismos criterios tecnocráticos de evaluación que se usan para el sistema judicial del Estado en su conjunto. Estos se pueden resumir en las siguientes interrogantes: ¿Cuántos juicios atienden los juzgados comunales? ¿Cuánto tiempo tardan en resolver un litigio? ¿Cuántas resoluciones de esos litigios se apelan? ¿Cuántas resoluciones se ejecutan?, entre las principales. Estos criterios responden a un sistema jurídico dominado por la burocracia - lo eficaz de ella para mejorar la economía procesal y la celeridad de los juicios - y por la violencia - la eficacia y coercibilidad de las sentencias emitidas por un juzgado-, y no a un sistema basado en la retórica cuya principal virtud es la posibilidad de acceso a la justicia, es decir, a una justicia conmensurable para las partes en sí mismas. De hecho esta evaluación ya ocurrió, después de poco más de medio año funcionando, y debido a «sus malos números» — poco más de una docena de asuntos-, el Supremo Tribunal de Justicia del Estado decidió recortar el personal de los juzgados comunales. De los cinco funcionarios con que originalmente se instituyeron se reubicó a dos de ellos en otros juzgados «donde sí se requería de su trabajo». 
Hasta la fecha esta es una cuestión que ha sido utilizada para atacar no solo a los juzgados comunales, sino al propio Derecho de los pueblos indígenas a utilizar sus sistemas jurídicos. Por ejemplo, en el mes de julio de 2008 el diputado encargado de la Comisión de Justicia del Congreso del Estado realizó un pronunciamiento en relación con que los juzgados comunales eran un fracaso, puesto que los indígenas no acudían a ellos y que solo absorbían los valiosos recursos del Supremo Tribunal. ${ }^{19}$ Al parecer este diputado no sabe que los funcionarios de los juzgados comunales son los que menos ganan en la estructura del Supremo Tribunal y que no cuentan siquiera con una línea telefónica propia.

En este mismo asunto del personal del juzgado se puede apreciar también un avance de la burocracia frente a la retórica. Por un acuerdo administrativo emitido por el Supremo Tribunal de Justicia del Estado se determinó que bastaba con que el juez fuera indígena para instalar el juzgado, sin importar que los demás funcionarios no lo fueran. Así se trató de instituir a los juzgados comunales en un principio, pero la presión del grupo de indígenas que aspiraba a convertirse en juez orilló a los funcionarios del poder judicial a instalar a otro funcionario indígena en cada sede de éstos, es decir, eran originalmente dos de cinco. Esta forma de integrar el personal del juzgado ha resultado muy conflictiva puesto que los demás funcionarios tienen fricciones en varias ocasiones con los jueces por las interpretaciones de la ley, o en la forma en que se desarrollan las audiencias. Esto ocurre particularmente en el juzgado de la región nahua donde, como ya lo decía, el juez lego se ve muy influenciado por las interpretaciones del secretario del juzgado, que es un abogado mestizo.

Este problema también se manifiesta de forma importante en el juzgado de la región purépecha, en donde el funcionario indígena, que no es el juez, realiza las funciones de los otros empleados — secretario de actas, notificador y escribiente-, puesto que los otros funcionarios no dominan el idioma purépecha, por lo que quedan relegados en las audiencias. Pero además como mestizos y funcionarios del Tribunal no son recibidos de buena manera en muchas de las comunidades indígenas, por lo que el actuario, de origen mestizo, no podía desempeñar su trabajo.

Los problemas que tendrán los juzgados comunales son previsibles, ambos tribunales fueron instituidos en cabeceras municipales. En el caso de la región purépecha, en la segunda ciudad más grande del estado, donde el Tribunal de Justicia ya 
contaba con infraestructura pero que resulta muy distante para muchas comunidades. Es fácil prever que los indígenas no acudirán en gran número a estos juzgados, ya que el factor económico pesa demasiado a la hora de trasportarse a las sedes de los juzgados comunales. Este aislamiento se ve potenciado por la cerrazón del Supremo Tribunal a facilitarles medios suficientes para su comunicación y difusión. De hecho, como ya lo advertí, los juzgados comunales son los únicos en la estructura del Supremo Tribunal que no cuentan con una línea telefónica propia; para comunicarse con los funcionarios de ese juzgado se requiere llamar a otro tribunal de mayor jerarquía y que les avisen que tienen una llamada. De esta manera este «experimento», como lo denominan varios de los funcionarios de primer nivel del poder judicial local, podría padecer el mismo problema que los juzgados del fuero común: la falta de posibilidad material para acceder a la justicia que imparte el Estado.

\section{A MODO DE COMENTARIOS FINALES}

En este trabajo he intentado defender la necesidad de recurrir a un abordaje teórico distinto para los nuevos campos jurídicos que representan los juzgados indígenas. Considero que la teoría de la articulación de los tres elementos de Boaventura de Sousa Santos es clarificadora para realizar un análisis interno del fenómeno de pluralismo jurídico que ahí se presenta. No solo porque permite observar los cambios, influencia y cruces entre sistemas jurídicos, sino porque además no es una teoría particular de un Derecho que intenta generalizarse a otros sistemas jurídicos.

En el caso particular de los juzgados comunales de Michoacán, la utilización de esta teoría muestra como, efectivamente, a través de estos nuevos aparatos jurisdiccionales el Estado está expandiendo su sistema de dominación, pero este avance lo vende como «reconocimiento» a los indígenas. El abordaje «interno» de este problema revela situaciones preocupantes y plantea varias interrogantes. Por ejemplo, en qué medida las estrategias externas de las organizaciones indígenas y sus aliados alcanzan para frenar la expansión del sistema de control estatal. Los juzgados indígenas pueden estar en manos de indígenas, pero la justicia que aplican puede trasformarse de tal manera que, sin dejar de ser un producto jurídico hibrido, ${ }^{20}$ sea un instrumento de refuncionalización del sistema de dominación jurídica estatal, ahora bajo el rótulo de «indígena». 
La oficialización de la diversidad cultural y jurídica no debe quedarse en un pronunciamiento que conserve o incremente las asimetrías sociales y jurídicas, o que incluso sirva de arma para desprestigiar las reivindicaciones de las organizaciones y pueblos indígenas. Esta es la versión que le sirve y promueve el capitalismo global, (Žižek 2005) y que a la larga puede ser un nuevo dispositivo de la tecnología de poder, de la dominación y de la domesticación (Assies 2001).

Me parece que estos cambios legales tendrían que estar basados en la idea de interculturalidad, como la entiende Catherine Walsh: «en la necesidad de construir relaciones entre grupos como también entre prácticas, lógicas y conocimientos distintos, con el afán de confrontar y trasformar las relaciones de poder -incluyendo las estructuras e instituciones de la sociedad - que han naturalizado las asimetrías sociales...» (Walsh 2002: 1). 


\section{BIBLIOGRAFÍA}

Agamben, Giorgio, 2006, Homo sacer. El poder soberano y la nuda vida. Pre-Textos, Valencia.

Aragón Andrade, Orlando y Gladys Montero Tapia, 2008, «Los pueblos indígenas ante la constitución de Michoacán». En Los derechos de los pueblos indígenas en México. Un panorama, coordinado por Orlando Aragón Andrade. Universidad Michoacana de San Nicolás de Hidalgo/ANUIES/Secretaría de Cultura del Estado/Congreso del Estado, México.

Assies, Willem, 1999, «Pueblos indígenas y reforma del Estado en América latina». En El reto de la diversidad, editado por Willem Assies, Gamma van der Haar, André Hoekema. El Colegio de Michoacán, México.

2001, «La oficialización de lo no oficial: ¿(re)encuentro de dos mundos?». Alteridades, n. 21. Universidad Autónoma Metropolitana-Iztapalapa.

Barié, Clestus Gregor, 2004, Pueblos indígenas y derechos constitucionales en América Latina: Un panorama. Instituto Indigenista Interamericano/Comisión Nacional para el Desarrollo de los Pueblos Indígenas/Abya-Yala, Bolivia.

Buenrostro Alba, Manuel, 2006, «La justicia indígena de Quintana Roo impartida por los jueces tradicionales mayas». Ponencia presentada en V Congreso de la Red Latinoamérica de Antropología Jurídica. Oaxtepec, México.

Carvalho Pacheco, Cristina, 2000, «Directrices del Banco Mundial para la reforma judicial de América Latina». El otro derecho, n. 25. Instituto Latinoamericano de Servicios Alternativos Legales.

Clavero, Bartolomé, 2008, Geografía jurídica de América Latina. Pueblos indígenas entre constituciones mestizas. Siglo XXI, México. 
Collier, Jane, 1995, «Problemas teórico metodológicos en la antropología jurídica». En Pueblos indigenas ante el derecho, coordinado por Victoria Chenaut y María Teresa Sierra. CIESAS/Centro Francés de Estudios Mexicanos y Centroamericanos, México.

Das, Veena y Deborah Poole (eds.), 2008, Anthropology in the margins of the state. School of American Research Press, Santa Fe.

Dezalay, Yves y Bryant G. Garth, 1996, Dealing in virtue. International commercial arbitration and the construction of a transnational legal order. University of Chicago Press, United States of America.

Domingo Barberá, Elia, 2005, «Ejemplos de pluralidad: La legislación en materia indígena en el estado de Quintana Roo». En Pluralismo jurídico y pueblos indígenas, coordinado por José Emilio Ordóñez Cifuentes. IIJ-UNAM, México.

Fix-Fierro, Héctor, 2003, «La reforma judicial en México: ¿De dónde viene? ¿Hacia dónde va?». Reforma judicial. Revista mexicana de justicia, n. 2. IIJ-UNAM, México.

Hernández, Rosalva Aída, Sarela Paz y María Teresa Sierra, 2004, El Estado y los indígenas en tiempos del PAN: neoindigenismo, legalidad e identidad. Miguel Ángel Porrúa/Centro de Instigaciones y Estudios Superiores en Antropología Social, México.

Gabbert, Wolfgang, 2006, «Los juzgados Indígenas en el sur de México». Ponencia presentada en V Congreso de la Red Latinoamericana de Antropología Jurídica. Oaxtepec, México.

González Galván, Jorge Alberto, 2004, «Las culturas indígenas y la constitución: Hacia una reglamentación del pluralismo jurídico en México». Ponencia 
presentada en el Congreso Internacional de Culturas y Sistemas Jurídicos Comparados. México, D. F.

Gutiérrez Rivero, Dea María, 2001, «Los juzgados de Conciliación en el Estado de Campeche». En Aproximaciones a la antropología jurídica de los mayas peninsulares, coordinado por Esteban Krotz. Programa de Naciones Unidas para el Desarrollo/Universidad Autónoma de Yucatán, México.

Lartigue, Francois y Diego Iturralde, 1995, «Antropología jurídica: Perspectivas de investigación». En Pueblos indígenas ante el derecho, coordinado por Victoria Chenaut y Teresa Sierra. Centro de Investigaciones y Estudios Superiores en Antropología Social/Centro Francés de Estudios Mexicanos y Centroamericanos, México, D. F.

Orantes García, José Rubén, 2007, Derecho pedrano. Estrategias jurídicas en los altos de Chiapas. Universidad Nacional Autónoma de México, México.

Poole, Deborah, 2006, «Los usos de la costumbre. Hacia una antropología jurídica del estado neoliberal». Alteridades, n. 31. Universidad Autónoma MetropolitanaIztapalapa.

Reyes, Javier y Pedro Ek Cituk, 2001, «Solución de controversias de acuerdo con la ley de justicia indígena del Estado de Quintana Roo». En Aproximaciones a la antropología jurídica de los mayas peninsulares, coordinado por Esteban Krotz. Programa de Naciones Unidas para el Desarrollo/Universidad Autónoma de Yucatán, México.

Rodríguez, César A. y Rodrigo Uprinmy, 2003, «¿Justicia para todos o seguridad para el mercado? El neoliberalismo y la reforma judicial en Colombia y en América Latina». En La falacia neoliberal. Crítica y alternativas, coordinado por Darío I. Botero Restrepo. Universidad Nacional de Colombia, Bogotá. 
Santos, Boaventura de Sousa, 1991a, «Derecho y comunidad: las transformaciones recientes de la naturaleza del poder del Estado en los países capitalistas avanzado». En Estado, derecho y luchas sociales, Boaventura de Sousa Santos. Instituto latinoamericano de Servicios Legales Alternativos, Bogotá.

1991b, «Una cartografía simbólica de las relaciones sociales: prolegómenos a una concepción posmoderna del derecho». En Estado, derecho y luchas sociales, Boaventura de Sousa Santos. Instituto latinoamericano de Servicios Legales Alternativos, Bogotá.

1997, La globalización del derecho. Los nuevos caminos de la regulación y la emancipación. Facultad de Derecho, Ciencias Políticas y Sociales/Instituto Latinoamericano de Servicios Legales Alternativos, Colombia.

2009a, «Sociología crítica de la justicia». En Sociología jurídica crítica. Para un nuevo sentido común en el derecho, Boaventura de Sousa Santos. Trotta/Instituto Latinoamericano de Servicios Alternativos Legales, Madrid.

2009b, «Pluralismo jurídico y las escalas del derecho: lo local, lo nacional y lo global». En Sociología jurídica crítica. Para un nuevo sentido común del derecho, Boaventura de Sousa Santos. Trotta/Instituto Latinoamericano de Servicios Legales Alternativos, Madrid.

Sierra, María Teresa, 1988, «Las conciliaciones indígenas». México indígena, n. 25. Instituto Nacional Indigenista, México.

1997, «Esencialismo y autonomía: paradojas en las reivindicaciones indígenas». Alteridades, n. 14. Universidad Autónoma Metropolitana, México.

2006, «Justicia indígena y Estado: retos desde la diversidad». Ponencia presentada en el V Congreso de la Red Latinoamericana de Antropología Jurídica, Oaxtepec, México. 
Suprema Corte de Justicia de la Nación, 2006, Libro blanco de la reforma judicial. Una agenda para la justicia en México. Suprema Corte de Justicia de la Nación, México.

Tamanaha, Brian Z., 2007, «La insensatez del "concepto científico" de pluralismo jurídico». En Pluralismo jurídico, Sally Engle Merry, John Griffiths y Brian Z. Tamanaha. Siglo del Hombre editores/Universidad de los Andes/Universidad Javeriana, Bogotá.

Terven Salinas, Adriana, 2005, «Revitalización de la costumbre jurídica en el juzgado indígena en Coetzalan. Retos desde el Estado». Tesis de maestría. Centro de Investigaciones y Estudios Superiores en Antropología Social, México, D. F.

Twining, William, 2005, Derecho y globalización. Siglo del Hombre editores, Colombia.

Valdés Ugalde, Francisco, 1993, «Concepto y estrategia de la "reforma del Estado"». Revista mexicana de sociología, n. 2. IIS-UNAM, México.

Ventura Patiño, María del Carmen, 2005, «Crónica de una reforma indígena fallida en Michoacán». Ponencia presentada en el IV Congreso de la Red de Investigadores de Gobiernos Locales Mexicanos, A. C. Guanajuato, México.

Walsh, Catherine, 2002, «Interculturalidad, reformas constitucionales y pluralismo jurídico». Publicación mensual del Instituto Científico de Culturas Indígenas, año 4 , n. 36.

Žižek, Slavoj, 2005, «Multiculturalismo, o la lógica del capitalismo multinacional». En Estudio culturales. Reflexiones sobre el multiculturalismo, Fredric Jameson y Slavoj Žižek. Paidós, Argentina. 


\section{Notas}

*El presente trabajo es una versión revisada de una ponencia presentada en el VI Congreso de la Red
Latinoamericana de Antropología Jurídica realizado en Bogotá en 2008 .
${ }^{1}$ Para conocer un panorama de los diferentes cambios constitucionales en América Latina véase, Barié
$(2004)$ y Clavero (2008).
${ }^{2}$ En este trabajo utilizaré indistintamente los términos sistema jurídico, sistema normativo y Derecho.
${ }^{3}$ Convenio 169 Sobre Pueblos Indígenas y Tribales en Países Independientes. Disponible en
http://www.ilo.org/ilolex/spanish/convdisp1.htm [consulta: 01/07/2004].
${ }_{4}^{4}$ Constitución Politica de los Estados Unidos Mexicanos, Diario Oficial de la Federación, 3 de agosto
${ }^{2001 .}$ Declaración de las Naciones Unidas sobre los Derechos de los Pueblos Indigenas. Disponible en
http://www.un.org/esa/socdev/unpfii/es/declaration.html [consulta: 14/07/2008]. ${ }^{6}$ Ley de Justicia Indígena para el Estado de Quintana Roo. Disponible en http://info4.juridicas.unam.mx/adprojus/leg/24/622/default.htm?s= [consulta: 24/06/2008].

7 Ley Orgánica del Poder Judicial del Estado de Campeche. Disponible en http://info4.juridicas.unam.mx/adprojus/leg/5/98/default.htm?s= [consulta: 24/06/2008].

${ }^{8}$ Ley Orgánica del Poder Judicial del Estado de Chiapas. Disponible en http://info4.juridicas.unam.mx/adprojus/leg/8/175/default.htm?s= [consulta: 24/06/2008].

9 Ley Orgánica del Poder Judicial del Estado de Puebla. Disponible en http://info4.juridicas.unam.mx/adprojus/leg/22/579/default.htm?s= [consulta: 24/06/2008].

${ }_{10}$ Ley de Justicia Comunal del Estado de Michoacán. Disponible en http://congresomich.gob.mx/congreso/Leyes/LEY\%20DE\%20JUSTICIA\%20COMUNAL\%20DEL\%20E STADO.htm [consulta: 24/06/2008].

${ }^{11}$ Para un análisis completo de las contradicciones en la reforma judicial en América Latina puede verse, Rodríguez y Uprimny (2003).

${ }_{12}$ Para profundizar en el nuevo rol del poder judicial frente a los otros poderes puede verse Santos (2009a: 81-128).

${ }^{13}$ De hecho la perspectiva teórica de pluralismo jurídico utilizada por las investigaciones desde la Antropología jurídica mexicana utilizan una idea que da cuenta de esta complejidad, que es la de la interlegalidad. Esta supone que el fenómeno de pluralismo jurídico se presenta como «la superposición, articulación e interpretación de varios espacios jurídicos mezclados» (Santos 1991b: 226).

${ }^{14}$ En ese mismo texto, Žižek realiza una cita de Alain Badiou que me parece muy ilustradora sobre la naturaleza del poder contemporáneo: «Puesto que está seguro de su capacidad para controlar todo el campo de lo visible y de lo audible a través de las leyes que gobiernan la circulación comercial y comunicación democrática, el Imperio ya no censura nada. Todo arte y todo pensamiento está perdido si aceptamos este permiso para consumir, para comunicar y para disfrutar» (Žižek 2005: 64).

15 Véase, Sierra (2006). También puede consultarse sobre este tipo de articulación en los sistemas normativos indígenas (Sierra 1988, Assies 2001).

${ }^{16}$ En este punto vale la pena recordar el debate Gluckman-Bohannan, famoso en la Antropología jurídica, sobre la aplicación de categorías analíticas propias de un Derecho occidental a los sistemas jurídicos nativos (Collier 1995).

${ }^{17}$ Véase, Constitución Politica del Estado de Michoacán de Ocampo, Periódico Oficial del Estado, 16 de marzo de 1998.

${ }^{18}$ De hecho, en la nueva propuesta de reforma constitucional que actualmente se está discutiendo con el nuevo gobernador, varias organizaciones indígenas están pidiendo el regreso de estos juzgados. Esta situación se da no porque rechacen el reconocimiento explícito de sus sistemas normativos, sino porque con la creación de los juzgados comunales la justicia indígena «oficial» fue sustraída de la comunidad.

${ }^{19}$ Véase, La voz de Michoacán, 14 de julio de 2008.

${ }^{20}$ Este término lo retomo de Orantes García (Orantes 2007). Es híbrido en el sentido de que es producto de más de dos sistemas normativos y de diferentes discursos jurídicos.

Fecha de recepción: 1 de abril de 2009.

Fecha de aceptación: 10 de octubre de 2009. 